\title{
Dipyridamole combined with exercise for thallium-201 myocardial imaging
}

\author{
P R WALKER, M A JAMES, R P H WILDE, * C H WOOD,* J RUSSELL REES \\ From the Departments of Cardiology and ${ }^{\star}$ Radiodiagnosis, Bristol Royal Infirmary, Bristol
}

SUMMARY A new stress test for thallium-201 myocardial imaging in which pharmacological coronary vasodilatation with dipyridamole is combined with dynamic exercise is described. In 38 patients with coronary artery disease the sensitivity, total number of defects, degree of redistribution, and visual quality of thallium-201 imaging were greater after dipyridamole with exercise testing than after exercise alone. When the data from these 38 patients were combined with the results of dipyridamole-exercise imaging in 49 patients in whom exercise electrocardiography had been inconclusive then the technique gave a sensitivity for coronary disease of $87 \%$ and a specificity of $92 \%$. Dipyridamole also increased the sensitivity of the exercise electrocardiogram, so that no patient with coronary disease had a strictly negative dipyridamole-exercise stress test. Only five of 214 patients who have now undergone this test have had complications requiring reversal of vasodilatation with aminophylline. The combined use of dipyridamole and exercise in this simple technique is a reliable and safe improvement on standard thallium-201 imaging tests.

Thallium-201 myocardial imaging is now an established technique for the diagnosis of coronary artery disease. ${ }^{12}$ Although thallium-201 scintigraphy performed after maximal exercise (exercise imaging) may possess greater sensitivity for coronary disease than does exercise electrocardiography, ${ }^{34}$ false negative scintigrams are still found in about $25 \%$ of patients. ${ }^{5-7}$ While computer assisted quantitation of scintigrams is said to give greater sensitivity than simple visual analysis, ${ }^{89}$ falsely negative results can still be expected when the stress imposed before thallium-201 injection is insufficient to produce regional differences in thallium-201 distribution.

The two widely used stress methods for thallium201 imaging are dynamic exercise and pharmacological coronary vasodilatation with dipyridamole. ${ }^{10}$ The purpose of these studies was to evaluate a simple technique in which maximal exercise testing is performed in the presence of a high plasma concentration of dipyridamole (a dipyridamole-exercise stress test). Studies of three groups of patients are described: in section 1 the sensitivity and quality of thallium-201 images obtained

Requests for reprints to Dr P R Walker, Department of Cardiology, Bristol Royal Infirmary, Bristol, Avon BS2 8HW.

Accepted for publication 7 January 1986 with the new method were compared with standard exercise imaging. The overall sensitivity and specificity of dipyridamole-exercise imaging were assessed in section 2, and in section 3 the optimal time for exercise testing after the large oral dose of dipyridamole was determined by serial measurement of plasma concentrations.

\section{Section 1: a comparison of dipyridamole-exercise imaging with standard thallium-201 imaging in patients with coronary artery disease}

PATIENTS AND METHODS

Thirty eight patients with stable mild or moderate angina pectoris were studied ( 35 male and three female; aged between 38 and 62 years, mean 50.5 years). The selection criteria were as follows: (a) no electrocardiographic or angiographic evidence of previous myocardial infarction; (b) no myocardial ischaemia (angina or ischaemic ST segment changes) during the first six minutes of a treadmill exercise test (modified Bruce protocol); (c) unequivocal evidence of coronary artery disease. Important lesions had been demonstrated in all 32 patients who had undergone coronary arteriography. The remaining six patients were middle aged men with typical angina and an ischaemic ST 
segment response during exercise, who may therefore be assumed to have had coronary disease ${ }^{1112}$ but whose symptoms did not warrant arteriography.

These criteria were designed to select those patients in whom standard thallium-201 imaging could be expected to show a relatively low sensitivity for coronary disease. ${ }^{313}$ By excluding patients with easily induced myocardial ischaemia the probability of angina being produced by dipyridamole alone was also reduced (unpublished observations).

Each patient gave informed consent to undergo exercise thallium-201 imaging on two separate occasions with a two week interval between tests. On one occasion, selected at random, exercise testing was preceded by the administration of dipyridamole as described below. On both occasions patients exercised to a symptom-limited end point and thallium201 ( $2 \mathrm{mCi}$ ) was injected intravenously 45 seconds before exercise was stopped.

\section{Protocol for dipyridamole-exercise testing}

At least two hours after a light breakfast the patient took $300 \mathrm{mg}$ of dipyridamole (three $100 \mathrm{mg}$ capsules of Persantin, Boehringer-Ingelheim) by mouth, having been informed that this unusually large dose might cause headache, mild chest discomfort, or a feeling of warmth. Forty five minutes later any symptoms were recorded, a modified 12 lead electrocardiogram was analysed, and a 19 gauge butterfly cannula was inserted into a dorsal hand vein. In the absence of severe angina or ST segment changes the patient started treadmill exercise approximately 60 minutes after dipyridamole. When severe angina or ST segment changes were produced by dipyridamole alone thallium-201 was injected at rest and this was followed immediately by a slow intravenous injection of aminophylline (125-250 mg). Thallium-201 imaging was then performed without exercise.

\section{Thallium-201 imaging}

Early thallium-201 images were recorded within 20 minutes of stress testing and late images four hours after testing by means of an IGE Maxicamera 400T gamma camera with a high resolution converging collimator. Planar images were obtained in the anterior, $45^{\circ}$ left anterior oblique, and $60^{\circ}$ left anterior oblique projections. A total of $\mathbf{4 0 0 0 0 0}$ events was collected for each image. The data were collected and processed by a Link Systems Dyanne computer. Five discrete regions of the left ventricular myocardium - anterolateral, apical, septal, inferior, and posterolateral-were defined. Each complete series of thallium-201 images (early and late) was inspected blindly and independently by three experienced observers. The images were analysed visually with and without smoothing, and in the first instance without contrast adjustment. It was agreed beforehand that any left ventricular region in which thallium-201 activity was at any point less than $75 \%$ of the maximum pixel value in the myocardial image should be classified as abnormal. Any disagreements were resolved by combined viewing of the images; after discussion the final judgment of the radiologist (RPHW) was accepted. Myocardial to background ratios were calculated for each set of images from the early $45^{\circ}$ left anterior oblique projection. The region showing the highest activity was compared with a background (that is, pulmonary) region that was 2 $\mathrm{cm}$ directly above the superior cardiac border on the computer display.

\section{Coronary arteriography}

Coronary stenoses shown by selective arteriography were defined as being "important" when they produced a $90 \%$ loss of cross sectional area (equivalent to a $67 \%$ diameter loss) in a major artery. Lesions producing $50-89 \%$ cross sectional area loss were defined as "minor" and of doubtful importance; and vessels with $0-49 \%$ loss were defined as "normal".

Statistical analysis was performed by Student's paired $t$ test.

\section{RESULTS}

In $80 \%$ of cases there was complete agreement between observers. The results of thallium-201 imaging after dipyridamole-exercise stress or exercise alone are summarised in Table 1 . Twenty eight patients showed regional abnormalities on both occasions, whereas six showed abnormalities only after

Table 1 Results of thallium-201 imaging after dipyridamole-exercise or exercise testing in 38 patients with coronary disease

\begin{tabular}{lll}
\hline Result & Dipyridamole-exercise & Exercise \\
\hline Patients with abnormal scintigrams & $34 / 38(89 \%)$ & $29 / 38(76 \%)$ \\
Total number of early defects & 74 & 56 \\
Total number of late defects & 20 & 28 \\
Percentage of defects showing redistribution & 73 & 50 \\
Myocardial to background ratio (mean $(\mathrm{SD}))$ & $3.44(0.57)^{\star}$ & $2.99(0.51)^{\star}$ \\
\hline
\end{tabular}

${ }^{\star} \mathbf{p}<0 \cdot 01$. 
(a)
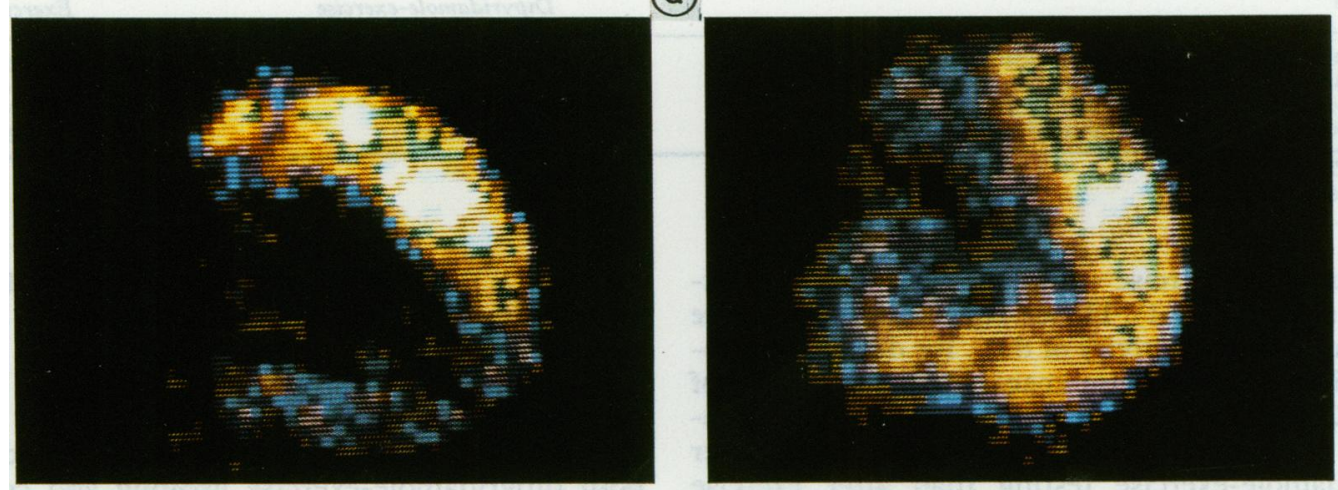

(b)
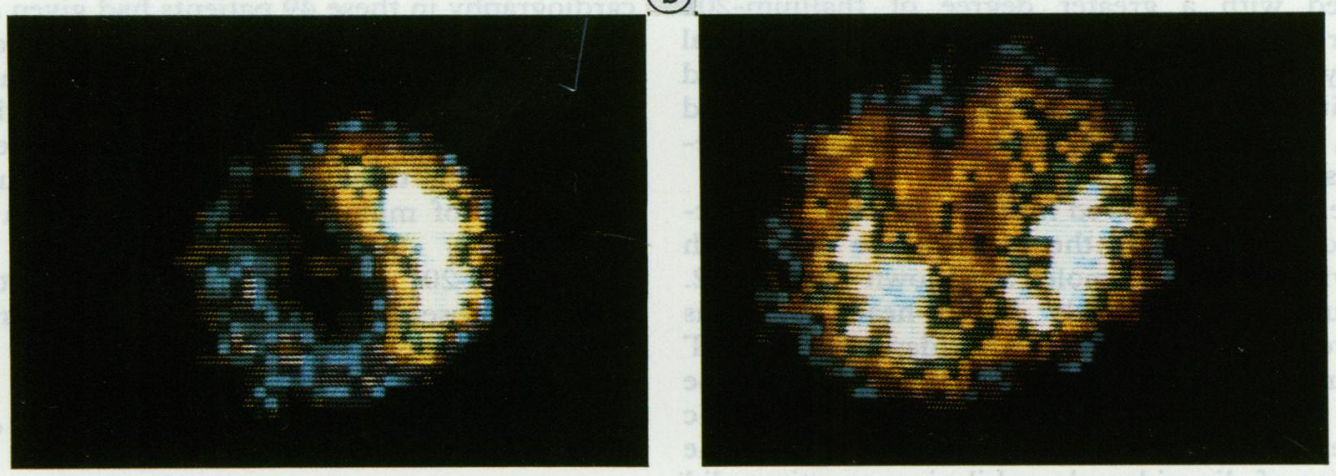

(c)
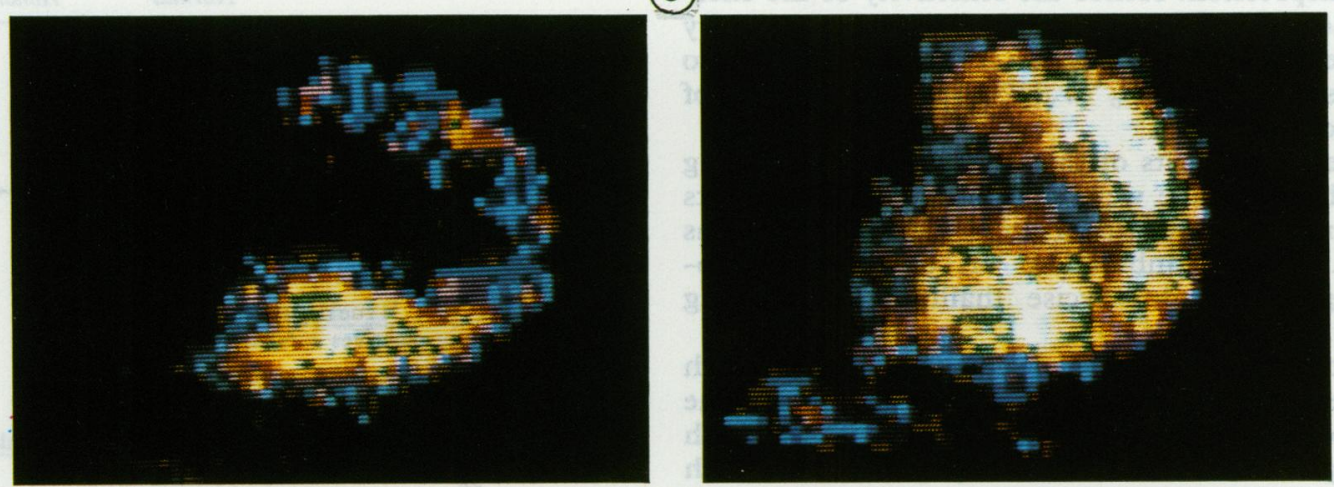

Fig. 1 Early thallium-201 images of three patients with coronary disease in whom dipyridamole-exercise imaging (left) showed abnormal regions whereas exercise imaging (right) did not. (a) Patient 1 (right coronary occlusion): inferior defect shown in anterior projection. (b) Patient 2 (right coronary occlusion, dominant vessel) inferior and septal defects in $45^{\circ}$ left anterior oblique projection. (c) Patient 3 (left anterior descending stenosis) anterolateral defect in anterior projection. 
Table 2 Changes in heart rate and electrocardiogram during exercise testing (with and without dipyridamole) in 38 patients with coronary disease

\begin{tabular}{lc}
\hline Variable & Dipyridamole-exercise \\
\hline Maximum heart rate (beats per minute) (mean (SD)) & $119(22)^{\star}$ \\
Maximum ST segment depression (mm) (mean (SD)) & $1 \cdot 7(1 \cdot 0)$ \\
Patients showing $>1$ mm ST segment depression & $32 / 38(84 \%)$ \\
Combined sensitivity of thallium-201 and ECG & $38 / 38(100 \%)$ \\
\hline
\end{tabular}

$\star \mathrm{p}<0.05$.

ECG, electrocardiogram.

dipyridamole-exercise stress and one only after exercise stress (Fig. 1). Hence dipyridamole-exercise imaging had a sensitivity of $89 \%$ for detecting coronary disease and exercise imaging had a sensitivity of $76 \%$. Considerably more abnormal regions were detected in the early images of the whole group after dipyridamole-exercise testing than after exercise imaging, whereas fewer were present in the late images; hence dipyridamole-exercise imaging was associated with a greater degree of thallium-201 redistribution than was exercise imaging. The visual quality of the thallium-201 images, as assessed quantitatively by their myocardial to background ratios, was significantly better after dipyridamoleexercise testing.

The changes observed in heart rate and the electrocardiogram during the two exercise tests (with and without dipyridamole) are shown in Table 2. Although a significantly lower heart rate was achieved in the presence of dipyridamole, mean ST segment depression was the same as after exercise alone. Three patients who did not show ischaemic ST depression during exercise alone did so in the presence of dipyridamole, while in no patient did dipyridamole prevent the development of ST segment depression. Hence the sensitivity of the exercise electrocardiogram for demonstrating coronary disease by ST segment depression was also increased-from $76 \%$ to $84 \%$-by the addition of dipyridamole.

When the results of thallium-201 stress imaging with dipyridamole were combined with the results of exercise electrocardiography the sensitivity was $100 \%$. The combination of exercise electrocardiography and exercise thallium-201 imaging gave a sensitivity of $95 \%$.

Two patients developed persistent angina with ST segment depression after dipyridamole alone and so did not proceed to the exercise phase. Both were given intravenous aminophylline, and both showed two regional abnormalities on early imaging with redistribution at four hours. Three other patients experienced mild short lived angina without ST segment depression after dipyridamole and were able to proceed to the exercise phase.
Section 2: determination of the sensitivity and specificity of dipyridamole-exercise thallium-201 imaging

\section{PATIENTS AND METHODS}

We added a further 49 patients who had undergone both dipyridamole-exercise imaging and coronary arteriography not more than six months apart to the 38 patients described in section 1. Exercise electrocardiography in these 49 patients had given a result which was either indeterminate or which had conflicted with the patient's history. All these patients met the first two selection criteria outlined in section 1 and had undergone dipyridamole-exercise imaging either to aid diagnosis or to evaluate the importance of minor coronary stenoses on angiography.

Thallium-201 images were analysed by two experienced observers (PRW and RPHW) using the method described in section 1 .

Table 3 Results of dipyridamole-exercise imaging and coronary arteriography in 87 patients

\begin{tabular}{lll}
\hline Coronary arteriograms & \multicolumn{2}{c}{ Thallium-201 imaging } \\
\cline { 2 - 3 } & Normal & Abnormal \\
\hline $\begin{array}{l}\text { Coronary disease demonstrated } \\
\text { or presumed }(\mathrm{n}=57)\end{array}$ & 7 & 50 \\
$\begin{array}{l}\text { Coronary disease not } \\
\text { demonstrated }(\mathrm{n}=25)\end{array}$ & 23 & 2 \\
$\begin{array}{l}\text { Minor coronary lesion present } \\
(\mathrm{n}=5)\end{array}$ & 3 & 2 \\
\end{tabular}

$$
\begin{aligned}
& \text { Sensitivity }=\frac{\text { True positives }}{\text { true positives + false negatives }} \times 100 \\
&=\frac{50}{50+7} \times 100=87 \% \\
& \text { Specificity }=\frac{\text { True negatives }}{\text { true negatives }+ \text { false positives }} \times 100 \\
&=\frac{23}{23+2} \times 100=92 \% \\
& \text { Predictive accuracy of a positive result }= \\
& \qquad \frac{\text { Number of diseased patients with positive result }}{\text { all patients with positive result }} \times 100 \\
&= \\
& \text { Predictive accuracy of a negative result }= \\
& \text { Number of disease-free patients with a negative result } \\
& \text { all patients with a negative result }
\end{aligned}
$$


RESULTS

The scintigraphic and angiographic findings are summarised in 'Table 3, with calculations of sensitivity, specificity, and predictive accuracy. Two patients with no coronary disease had a false positive scintigram-one had severe mitral regurgitation and gross electrocardiographic abnormalities, while in the other patient, who was shown to have a mild dilated cardiomyopathy, no dipyridamole could be detected in the plasma; hence it may be assumed that standard exercise imaging would also have produced a positive result in this patient. The five patients with coronary lesions of doubtful importance were excluded from the calculations.

\section{Section 3: determination of optimal interval from dipyridamole to exercise testing - measurement of plasma concentrations}

Sixteen patients undergoing dipyridamole-exercise testing agreed to serial venous blood sampling via an indwelling cannula at the times shown in Fig. 2. In one patient no dipyridamole could be detected in any sample and his results were excluded.

Mean dipyridamole concentration reached a peak 60 minutes after ingestion, although values that were almost as high were measured at $40,80,100$, and 120 minutes after. At 300 minutes (when the redistribution images were being recorded) the mean concentration had fallen to $26 \%$ of the peak value.

Individually, 11 patients showed evidence of rapid absorption, whereas in three patients absorption was apparently much slower with peak values not being reached until after 120 minutes (Fig. 3).

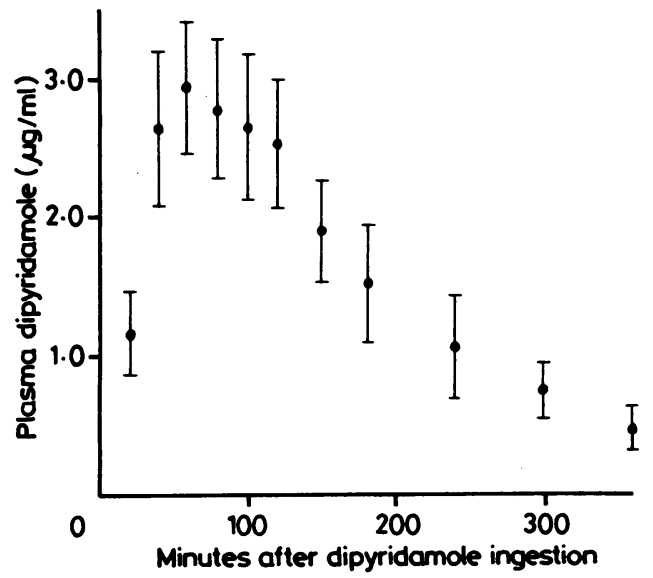

Fig. 2 Rate of clearance of $300 \mathrm{mg}$ dipyridamole in 15 patients. Values are mean (SEM).

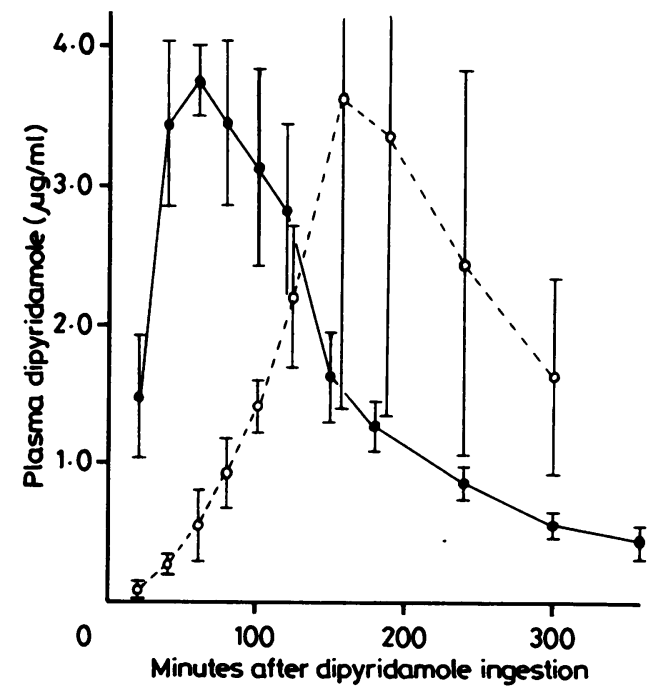

Fig. 3 Rate of clearance of dipyridamole in 11 early absorbers ( -1 ) and three late absorbers ( $\mathrm{O}_{---} \mathrm{O}$ ). Values are mean (SEM).

One patient (not included in Fig. 3) apparently absorbed very little dipyridamole, since his peak plasma concentration was only $0.69 \mu \mathrm{g}$ per $\mathrm{ml}$.

\section{Discussion}

\section{RATIONALE OF DIPYRIDAMOLE-EXERCISE TESTING}

These studies have demonstrated that pharmacological coronary vasodilatation with dipyridamole superimposed on exercise stress can result in an abnormal scintigram in patients with false negative scintigrams after exercise alone. Two actions of dipyridamole may be responsible. Firstly, dipyridamole is a potent coronary arterial dilatator that acts selectively on the coronary resistance bed. ${ }^{14}$ When injected intravenously at maximal exercise, dipyridamole produces an increase in coronary flow greater than that produced by exercise alone. ${ }^{15}$ Intravenous dipyridamole combined with isometric handgrip exercise produces a greater increase in coronary flow than does either type of intervention alone, with the levels of flow (3.3 times the baseline values) exceeding any previously reported for the human coronary circulation. ${ }^{16}$ Since dynamic exercise is associated with a greater increase in coronary flow than is isometric exercise ${ }^{17}$ it is probable that dipyridamole-exercise stress increases coronary flow to an equal or even greater degree than dipyridamole combined with isometric handgrip.

The amount of thallium-201 entering myocardial 
cells is determined not only by coronary flow but also by how much dipyridamole is extracted-that is the extraction fraction. ${ }^{18}$ When coronary flow is increased out of proportion to oxygen consumption, as occurs during dipyridamole induced vasodilatation, ${ }^{16} 18$ the extraction fraction falls. Dynamic exercise on the other hand increases oxygen consumption and hence thallium-201 extraction; however, in regions in which myocardial ischaemia occurs the ability to extract thallium-201 is reduced. ${ }^{18}$ In the present studies as in others ${ }^{1319}$ dipyridamole infrequently caused myocardial ischaemia; in contrast exercise consistently produced angina or ST segment depression or both. In theory the combined stress of dipyridamole and exercise should therefore maximise regional differences in thallium-201 distribution in patients with coronary disease by the differing effects of both interventions on the delivery and extraction of the radionuclide.

A second property of dipyridamole is its undisputed ability to produce myocardial ischaemia in patients with coronary disease. ${ }^{19-21}$ Although patients with easily induced myocardial ischaemia were excluded from the present study, two patients developed angina after dipyridamole which was severe enough to require reversal by aminophylline. Five other patients either experienced mild angina after dipyridamole or demonstrated evidence of ischaemia considerably earlier in their exercise test. Two mechanisms may be responsible for the production of ischaemia: firstly, perfusion of the subendocardium may fall when flow across a stenosis of the nutrient artery is increased by, for example, vasodilatation. ${ }^{22}$ Secondly, dilatation of resistance vessels in well perfused regions may produce steal from regions which are dependent on a collateral circulation. ${ }^{23} 24$ There were 11 patients in whom dipyridamole undoubtedly produced myocardial ischaemia or was essential for the production of an abnormal scintigram; four of seven in whom angiography was performed were shown to have collateral dependent regions of viable myocardium.

The extent to which each of these two properties of dipyridamole was responsible for the improved sensitivity of dipyridamole-exercise imaging is uncertain. If, as seems probable, thallium-201 uptake by the lungs is not significantly affected by dipyridamole, 20 then the increased myocardial to background ratio observed with dipyridamoleexercise testing, which was responsible for the improved visual quality of the images, may be presumed to result primarily from increased myocardial blood flow. The finding that in four of the six patients in whom only dipyridamole-exercise imaging was abnormal the myocardial to background ratio was not enhanced suggests, however, that the pro- duction of ischaemia by dipyridamole must also play an important role.

\section{SENSITIVITY AND SPECIFICITY OF}

THALLIUM-201 IMAGING

The overall sensitivity for coronary disease of dipyridamole-exercise scintigraphy (the truepositive rate) was $87 \%$; this was $13 \%$ better than the sensitivity of the standard exercise imaging. Others have reported a sensitivity of between $67 \%^{19}$ and $95 \%{ }^{8}$ with exercise imaging and of between $67 \%{ }^{19}$ and $93 \%{ }^{25}$ with intravenous dipyridamole imaging. The overall sensitivity of exercise imaging was $82 \%$ in 1077 patients who had this test from 1976 to $1979^{26}$; however, these patients were unselected as regards disease severity, and many had previous myocardial infarction. Patient characteristics which tend to increase the sensitivity of thallium-201 imaging include previous myocardial infarction, ${ }^{27} \mathrm{im}$ paired left ventricular function, ${ }^{13}$ severe coronary disease, ${ }^{37}$ and an ineffective collateral circulation ${ }^{28}$; while the method of image interpretation (visual or quantitative) and the criteria used to define abnormality are also important determinants of sensitivity. In the present studies patients with previous infarction, poor left ventricular function, and severe coronary disease-the correlate of an early positive exercise test ${ }^{29}$-were excluded; while the criterion for abnormality (that is a $\geqslant 25 \%$ deficiency of thallium-201 activity) was relatively strict and the method of interpretation was visual. Hence in a less carefully selected population and using a more refined method of interpretation an even higher sensitivity could no doubt have been achieved. It should be stressed, however, that any figure quoted for the sensitivity of a test is meaningful only when derived by studying the population in which the test will find clinical application-that is in symptomatic patients with conflicting or indeterminate exercise electrocardiograms. ${ }^{356}$

Dipyridamole-exercise imaging achieved a specificity (true-negative rate) of $92 \%$ in 25 patients without important coronary disease. False positive results, of which there were two, occurred only in patients with other cardiac lesions who were therefore likely to show scintigraphic abnormalities. ${ }^{30}$ No patient with a normal heart had an abnormal scintigram. In the cumulative data referred to above ${ }^{26}$ the overall specificity of exercise thallium-201 imaging in symptomatic patients was $90 \%$. In individual studies the estimates of specificity, which have ranged from $67 \%{ }^{13}$ to $100 \%,^{3}$ have often been based upon very small patient numbers. As with test sensitivity, patient selection is all important in the determination of specificity. The present study also shows that the inclusion of subjects who have other 
important cardiac lesions in a population with no coronary disease reduces the specificity of the test being evaluated. Again, both the criteria by which normality is defined and the method of image interpretation will further influence specificity. When visual analysis has been used the criterion for an abnormal region has been a reduction of between $15 \%{ }^{3}$ and $50 \%{ }^{4}$ of peak myocardial activity; while in many studies no criteria were defined. ${ }^{51319}$ Francisco et al were able to improve their specificity of $67 \%$ obtained with a computer enhanced visual or tomographic analysis to $96 \%$ by the use of a quantitative tomographic method. ${ }^{13}$ In the present study the criterion for abnormality of a relative reduction in thallium-201 activity of at least $25 \%$ as assessed by computer assisted visual analysis was associated with an $80 \%$ inter-observer agreement and with high values for both sensitivity and specificity. This criterion is therefore recommended for the routine interpretation of dipyridamole-exercise images.

IMPORTANCE OF THE ELECTROCARDIOGRAM Proper assessment of the result of a dipyridamoleexercise test should include analysis of both the scintigram and the exercise electrocardiogram. ${ }^{2}$ Comparison of the electrocardiogram recorded during dipyridamole-exercise or exercise testing (section 1) showed that in the presence of dipyridamole an identical average amount of ischaemic ST segment depression occurred but at a significantly lower maximal heart rate. In three patients ischaemic ST depression was seen only in the presence of dipyridamole, and this increased the sensitivity of the electrocardiogram from $76 \%$ to $84 \%$. Others have assessed the diagnostic value of electrocardiographic changes produced by the infusion of dipyridamole, and they obtained low values for sensitivity and specificity. ${ }^{3132}$ If in the present study, however, an abnormal dipyridamoleexercise test result is defined as either an ischaemic ST segment response or an abnormal scintigram the sensitivity in all 57 patients with coronary disease in section 2 rises from $87 \%$ to $96 \%$, while the predictive accuracy of a negative result (that is no scintigraphic or electrocardiographic abnormality) increases from $76 \%$ to $92 \%$. In those two patients with coronary disease in whom no electrocardiographic or scintigraphic abnormalities were observed the maximal heart rate was less than the $85 \%$ of predicted maximal rate required for a truly negative exercise test. Thus no patient with coronary disease could be said to have had a completely negative dipyridamole-exercise test.

DIAGNOSTIC VALUE OF REDISTRIBUTION Redistribution of thallium-201 into regions showing defects in early images is due primarily to delayed washout of thallium-201 from ischaemic myocardium. ${ }^{33}$ The absence of redistribution four to six hours after injection is most often due to the presence of a myocardial scar ${ }^{34}$ but may be seen in an area of viable myocardium whose blood supply is severely compromised. In such instances redistribution may be delayed until 18-24 hours. ${ }^{35} \mathrm{Al}$ though in earlier studies the diagnostic value of redistribution was not emphasised data from these studies ${ }^{35}$ did suggest that "reversible" defects, that is those associated with redistribution, may be more specific indicators of coronary disease than "irreversible" defects. In the present study redistribution was seen in a greater percentage of defects detected after dipyridamole-exercise testing than in those detected after exercise alone. Moreover, all 70 reversible defects produced by dipyridamoleexercise testing were in patients with important coronary disease (predictive value $=100 \%$ ), whereas three of 29 irreversible defects were in patients with no coronary disease (predictive value $=89 \%$ ). Since the proper selection of patients for dipyridamoleexercise imaging excludes patients with previous myocardial infarction or easily induced ischaemia during exercise or both, a "defect" seen after dipyridamole-exercise testing which shows no redistribution should thus be interpreted with caution.

Only one patient had an abnormal scintigram on exercise testing but not on dipyridamole-exercise testing. This patient's oxygen consumption and the severity of myocardial ischaemia, as judged by maximal heart rate and ST segment depression recorded during exercise, were virtually identical on both occasions. Coronary arteriography showed a single $90 \%$ stenosis of the mid-left anterior descending coronary artery and exercise imaging demonstrated (on one projection only) an inferior defect which at four hours showed no redistribution. Since there is a fairly precise correlation between the site of scintigraphic abnormalities and the location of coronary stenosis in patients with single vessel disease, ${ }^{36}$ both the location and the absence of redistribution cast some doubt on the importance of this defect. In contrast in those four patients in whom only dipyridamole-exercise imaging was abnormal and in whom arteriography was performed, all defects were appropriately situated and demonstrated redistribution.

The safety and low complication rate of this technique, in which two potent stresses are being imposed together on the myocardium, depend on careful patient selection-that is the exclusion of patients with easily induced myocardial ischaemia. There have been no serious complications in the 214 patients who have undergone dipyridamole-exercise 
thallium-201 imaging. Three per cent of patients had side effects of dipyridamole requiring reversal by aminophylline. These were prolonged angina (two patients), severe headache (two patients), and vomiting (one patient). In only three patients has the exercise phase not been possible.

Patients with coronary disease who have myocardial ischaemia within the first stage of the Bruce protocol have severe disease and a relatively poor prognosis. ${ }^{29} 37$ Unlike patients with symptoms suggestive of ischaemic heart disease but in whom the exercise electrocardiogram is negative or equivocal, diagnosis is not difficult in such patients and they do not require thallium-201 imaging.

Dipyridamole-exercise testing appears to be better than standard exercise testing in terms of sensitivity and quality of thallium-201 imaging. In patients selected on the basis of an inconclusive exercise electrocardiogram the technique is safe, effective, and very simple.

We thank the nuclear imaging and cardiology technicians for their great contribution to this work, $\mathrm{Dr}$ D Davies of the University of Bath and BoehringerIngelheim for the dipyridamole assays and Professor $\mathrm{K}$ Lance Gould for his advice and encouragement.

\section{References}

1 Corne RA, Gotman MS, Atlan H. Fundamentals of clinical cardiology: radionuclide assessment of regional myocardial perfusion with thallium-201. Am Heart $\mathcal{f}$ 1979; 97: 112-7.

2 Melin JA, Piret LJ, Vanbutsele RJM, et al. Diagnostic value of exercise electrocardiography and thallium myocardial scintigraphy in patients without previous myocardial infarction: a Bayesian approach. Circulation 1981; 63: 1019-24.

3 Bailey IK, Griffiths LSC, Rouleau J, Strauss HW, Pitt B. Thallium-201 myocardial perfusion imaging at rest and during exercise. Comparative sensitivity to electrocardiography in coronary artery disease. Circulation 1977; 55: 79-87.

4 Ritchie JL, Trobaugh GB, Hamilton GW, et al. Myocardial imaging with thallium-201 at rest and during exercise. Comparison with coronary arteriography and resting and stress electrocardiography. Circulation 1977; 56: 66-71.

5 Botvinick EH, Taradash MR, Shames DM, Parmley WW. Thallium-201 myocardial perfusion scintigraphy for the clinical clarification of normal, abnormal and equivocal electrocardiographic stress tests. Am $\mathcal{f}$ Cardiol 1978; 41: 43-51.

6 Hamilton GW, Trobaugh GB, Ritchie JL, Gould KL, DeRouen TA, Williams DL. Myocardial imaging with thallium-201: an analysis of clinical usefulness based on Bayes' theorem. Semin Nucl Med 1978; 8: 358-64.

7 Ritchie JL, Zaret BL, Strauss HW, et al. Myocardial imaging with thallium-201: a multicenter study in patients with angina pectoris or acute myocardial infarction. Am $\mathcal{F}$ Cardiol 1978; 42: 345-50.

8 Vogel RA, Kirch DL, LeFree MT, Rainwater JO, Jenson DP, Steele PP. Thallium-201 myocardial perfusion scintigraphy: results of standard and multi-pinhole tomographic techniques. Am $\mathcal{F}$ Cardiol 1979; 43: 787-93.

9 Garcia E, Maddahi J, Berman D, Waxman A. Space/time quantitation of thallium-201 myocardial scintigraphy. I Nucl Med 1981; 22: 309-17.

10 Zaret BL, Berger HJ. Techniques of nuclear cardiology. In: Hurst JW, Logue RB, Rackley CE, et al, eds. The heart. New York: McGraw-Hill, 1982: 1803-43.

11 Detry J-MR, Kapita BM, Cosyns J, Sottiaux B, Brasseur LA, Rousseau MF. Diagnostic value of history and maximal exercise electrophysiology in men and women suspected of coronary heart disease. Circulation 1977; 56: 756-61.

12 Weiner DA, Ryan TJ, McCabe CH, et al. Exercise stress testing. Correlations among history of angina, ST-segment response and prevalence of coronaryartery disease in the Coronary Artery Surgery Study (CASS). $N$ Engl f Med 1979; 301: 230-5.

13 Francisco DA, Collins SM, Go RT, Ehrhardt JC, Kirk OCV, Marcus ML. Tomographic thallium-201 myocardial perfusion scintigrams after maximal coronary artery vasodilatation with intravenous dipyridamole: comparison of qualitative and quantitative approaches. Circulation 1982; 66: 370-9.

14 Kinsella D, Troup W, McGregor $M$. Studies with a new coronary vasodilator drug: Persantin. Am Heart $\mathcal{f}$ 1962; 63: 46-51.

15 Barnard RJ, Duncan HW, Livesay JJ, Buckerg GD. Coronary vasodilatation reserve and flow distribution during near-maximal exercise in dogs. 7 Appl Physiol 1977; 43: 988-92.

16 Brown BG, Josephson MA, Petersen RB, et al. Intravenous dipyridamole combined with isometric handgrip for near maximal increase in coronary flow in patients with coronary artery disease. Am $\mathcal{f}$ Cardiol 1981; 48: 1077-85.

17 Lowe DK, Rothbaum DA, McHenry PL, Corya BC, Knoebel SB. Myocardial blood flow response to isometric (handgrip) and treadmill exercise in coronary artery disease. Circulation 1975; 51: 126-31.

18 Weich HF, Strauss HW, Pitt B. The extraction of thallium-201 by the myocardium. Circulation 1977; 56: 188-91.

19 Albro PC, Gould KL, Westcott RJ, Hamilton GW, Ritchie JL, Williams DL. Noninvasive assessment of coronary stenoses by myocardial imaging during pharmacologic coronary vasodilatation. III. Clinical trial. Am $\mathcal{F}$ Cardiol 1978; 42: 751-60.

20 Gould KL, Westcott RJ, Albro PC, Hamilton GW. Noninvasive assessment of coronary stenoses by myocardial imaging during pharmacologic coronary vasodilatation. II. Clinical methodology and feasibility. $\mathrm{Am}$ f Cardiol 1978; 41: 279-87.

21 Timmis AD, Lutkin JE, Fenney LJ, et al. Comparison of dipyridamole and treadmill exercise for enhancing thallium-201 perfusion defects in patients with coronary artery disease. Eur Heart $\mathcal{F}$ 1980; 1: 275-80. 
22 Gould KL, Lipscomb K, Calvert C. Compensatory changes of the distal coronary vascular bed during progressive coronary constriction. Circulation 1975; 51: 1085-94.

23 Wilckden DEL, Paoploni HJ, Eikens E. Evidence for intravenous dipyridamole producing a coronary steal effect in the ischaemic myocardium. Aust NZ $\mathcal{Y}$ Med 1971; 1: 8-14.

24 Becker LC. Conditions for "coronary steal" with dipyridamole [Abstract]. Am F Cardiol 1976; 37: 120.

25 Leppo J, Boucher CA, Okada RD, Newell JB, Strauss HW, Pohost GM. Serial thallium-201 myocardial imaging after dipyridamole infusion: diagnostic utility in detecting coronary stenoses and relationship to regional wall motion. Circulation 1982; 66: 649-57.

26 Pohost GM, Alpert NA, Ingwall JS, Strauss HW. Thallium-201 redistribution: mechanisms and clinical utility. Semin Nucl Med 1980; 10: 70-93.

27 Uhl GS, Kay TN, Hickman JR. Computer-enhanced thallium scintigrams in asymptomatic men with abnormal exercise tests. Am $\mathcal{F}$ Cardiol 1981; 48: 1037-43.

28 Wainwright RJ, Maisey MN, Edwards AC, Sowton E. Functional significance of coronary collateral circulation during dynamic exercise evaluated by thallium201 myocardial scintigraphy. $\mathrm{Br}$ Heart $\mathcal{f}$ 1980; 43: 47-55.

29 Goldschlager N, Selzer A, Cohn K. Treadmill stress tests as indicators of presence and severity of coronary artery disease. Ann Intern Med 1976; 85: 277-86.

30 Dunn RF, Uren RF, Sodick N, et al. Comparison of thallium-201 scanning in idiopathic dilated cardio- myopathy and severe coronary artery disease. Circulation 1982; 66: 804-10.

31 .DeAmbroggi L, Bargieri P, DeBiase AM. Assessment of diagnostic value of dipyridamole testing in angina pectoris. Clin Cardiol 1982; 5: 269-74.

32 Tavazzi L, Previtali M, Salerno JA. Dipyridamole test in angina pectoris: diagnostic value and pathophysiological implications. Cardiology 1982; 69: 34-41.

33 Grunwald AM, Watson DD, Holzgrefe $\mathrm{HH}$, Irving JF, Beller GA. Myocardial thallium-201 kinetics in normal and ischaemic myocardium. Circulation 1981; 64: 610-8.

34 Verani MS, Jhingran S, Attar M, Rizk A, Quinones MA, Miller RR. Post-stress redistribution of thallium201 in patients with coronary artery disease, with and without prior myocardial infarction. Am $\mathcal{F}$ Cardiol 1979; 43: 1114-22.

35 Gutman J, Berman DS, Freeman M, et al. Time to completed redistribution of thallium-201 in exercise myocardial scintigraphy: relationship to the degree of coronary artery stenosis. Am Heart $\mathcal{f}$ 1983; 106: 989-95.

36 Dunn RF, Freedman M, Bailey IK, Uren RF, Kelly DT. Localization of coronary artery disease with exercise electrocardiography: correlation with thallium-201 myocardial perfusion scanning. Am f Cardiol 1981; 48: 837-43.

37 Bruce RA, DeRouen T, Peterson DR, et al. Noninvasive predictors of sudden cardiac death in men with coronary artery disease. Predictive value of maximal stress testing. Am $\mathcal{F}$ Cardiol 1977; 39: 833-40. 